\title{
Green Synthesis of Silver Nanoparticles for Various Biomedical and Agro Industrial Application
}

\author{
Abaysew Ayele*, Rita S. Mujmdar, Tesfaye Addisu, Yohannes Woinue \\ School of Basic Science and Research, Biotechnology Department, Shrada University, Greater Noida - 201 310, Uttar Pradesh, India.
}

\section{A R T I C LEDETAILS}

Article history:

Received 20 April 2019

Accepted 08 May 2019

Available online 20 May 2019

\section{Keywords:}

Silver Nanoparticles

Nano-Fertilizer

Oncology

Nano-Sensor

\begin{abstract}
A B S T R A C T
Silver nanomaterials have been integrated into industrial, biomedical and agricultural application, including biosensor, anti-microbial, anti-tumor, drug delivery, waste treatment, coated fabrics and nano fertilizer. Nanoparticle possesses unusual character due to their large surface area to volume ratio and an extraordinary catalytic activity, electronic properties, optical properties and anti-microbial activity while they are constructed in atomic level. The unique and major task in the synthesis of nanoparticle is choosing of an advanced and ecofriendly method. Nevertheless, physical and chemical methods of synthesis of nanoparticles are too expensive and environmentally unsound. In this study, the green synthesis of nanoparticle's production methods was evaluated on the basis of various literatures. Currently, there is a better possibility of using green synthesis of silver nanoparticles, especially a plant, bacterial and fungal production of nanoparticles which is emerging as a novel ecofriendly technique. The growth rate of bacterial culture, the extract of plant secondary metabolite and mycelial surface area of fungus are the main comprehensible mechanism in green synthesis of silver nanoparticles. The silver nanoparticles, which are produced through green biosynthesis is safe and hold a better possibility to be administered for medical and agricultural usages. Over all we found that the fungal green biosynthesis of silver nanoparticles is considered more preferable and is excellently chosen in it in industrial level production.
\end{abstract}

\section{Introduction}

Of several nanostructure types, metal nanoparticles which have a high precise surface area to volume ratio and a high fraction of surface atoms, so have been attracting considerable attention and studied extensively because of their exceptional phytochemical features, including catalytic activity, electronic properties, optical properties, anti-microbial activity, and magnetic properties [1]. This is therefore well understood of the synthesis mechanism, determining of the crystal structure of silver nanoparticles is a vital point of views.

It was when it came to a traditional way, such as physical and chemical methods of synthesis silver nanoparticles are used to date. However, there is a growing need to using environmentally friendly biological synthesis of nanoparticles is better to in minimizing cost, labor and environmental hazards [2]. That's why, biosynthesis of silver nanoparticles uses them extensively and are the primary provider of environmental protection and human health care. The discharge of chemical agent toxicity effect has a worry in environmental policy. The silver nanoparticles, which are formed using chemical method may verify hazards in the field of their application in biomedical tools [3]. Physical methods need expensive equipment and large space for their setup. Even if the physical method of radiation has speed and no hazardous use of chemical agents, it has low yield and high energy consumption in addition to pulsed higher laser deposition $[4,5]$.

Among ecofriendly biosynthesis of silver nanoparticles, using of fungus is desirable for industrial level production since which have been secreted high amount of a bulk of metabolites or bioactive compounds in a short period of time and ease in down processing. Their mycelia that provide a much higher surface area than bacteria and allow high production of the desired products $[6,7]$. However, understanding of the breakdown of bulk materials through extracellular bioactive compounds into nanoparticles is not yet explored too far [8]. While silver nanoparticles tools have an immeasurable advantage in human daily use, the industrialized production of the particles must be reasonably priced and environmentally sound.

\section{Origin and Concept of Nanoparticles}

The prefix "nano" derive from the Greek word "nanos" mean "dwarf" is a common word in literatures. The word "nano" donates one billionth of a meter or $10^{-9}$. The word nanotechnology was coined by professor Norio Taniguchi of Tokyo Science University in 1974 to illustrate precision manufacturing of materials at the nanometer level [9]. And the concept of nanotechnology at the first time was illustrated by Richard Feynman in a lecture entitled "There's plenty of room at the bottom" at the American Institute of Technology in 1959. Although the size of nano in numerous, the range of nanoparticles include from 1 to $100 \mathrm{~nm}$ and are commonly synthesized by using two strategies. Either top-down or bottom-up technical strategies [10].

Materials of bulk size have been shown constant physical properties due to its large size. However, diminution of the size of nanoparticles have a significant effect on physical properties which totally different from the bulk materials. Unlike bulk materials, nanoparticles have characteristic physical, chemical, electronic, electrical, mechanical, magnetic, thermal, dielectric, optical and biological properties [11, 12]. Nanoparticles effective over bulk materials due to their surface plasmon resonance (SPR), enhanced Rayleigh scattering and surface enhanced Raman scattering (SERS) in metal nanoparticles, quantum size effect in semiconductors and super magnetism in magnetic materials. Therefore, nanoparticles are considered as building blocks of the next generation of optoelectronics, electronics, and various antibiotics, chemical and biochemical sensors $[13,14]$. Alongside this, the nature of nanotechnology is a multi-disciplinary area like bio-nanotechnology in the scientific world where the various researches take place [15].

\section{Principle of Silver Nanoparticles (AgNPs)}

Many researches have been investigated on different metallic nanoparticles such as platinum and palladium (Pt \& Pd) [16]. Gold (Au) [17] and Silver (Ag) [18]. Due to their large surface area to volume ratio, silver nanoparticles more prefer an anti-microbial activity which provides high affinity to contact the body of microorganisms. Because of this fact, metallic silver nanoparticles can be applied in the fields of molecular medicine, textile fabrics, dental materials, water treatment, food packaging, bio-labeling-sensor and in wound healing purpose. Why the 
silver nano particles being a center of attraction in those biomedical and industrial and have preferred? since AgNPs possess low toxicity on human cell and good biocompatibility, low volatile and high thermal stability [19, -23]. Beside to that here is a concrete scientific evidence why AgNPs being a choice of producing nano silver coated biomaterials, Ag ions has longterm antibacterial activity, due to sustained ion release [24] and low bacterial resistance [25].

Silver nanoparticles are popular whereas it has been used as antibiotics, which intermediate by metallic ion $\left(\mathrm{Ag}^{0}\right)$. The metallic ions own mode of action and bactericidal effect, but not yet defined its biochemical pathway. However, it is suggested that the silver nanoparticles attach to the cell wall and restrict the permeability of ions resulting the cytosol discharge and cellular respiration defects [26]. On the other side there is a controversial scientific view regarding to nanoparticles which would bind to the protein functional groups and hinder the gene expression.

\section{Biosynthesis of Silver Nanoparticles}

There are several ways of metallic nanoparticle synthesis methods. To date physical, chemical and biological reduction approaches were engaged in the synthesis of metallic AgNPs [27-30]. Despite if those methodologies have been practiced in production of nanoparticles, a chemical agent toxicity effect has a worry in environmental policy. Even if the physical method of radiation has speed and no hazardous as of chemical agents, it has low yield and high energy consumption [31]. Unlike physical and chemical processing, biological synthesis is further favor in which the biological system provides an innovative research idea in nano scale materials production [32]. Numerous researchers suggested that using of biological synthesis of AgNPs, without using of expensive and hazardous chemical agents such as organic solvents and toxic reducing agent, is elegant to enhance environmentally friendly technologies. Consequently, biosynthesis strategies are very simple techniques and cost effect no prolonged time required as of chemical and physical procedures.

\subsection{Synthesis of AgNPs using Bacteria}

Nowadays, there is a growing need to develop eco-friendly process. Thus, using of plants [33] and microorganisms [34] are suitable techniques in synthesis of AgNPs. As a result, researchers have turned to biological synthesis because through this biological synthesis obtaining particles with good control on the size distribution than the other traditional methods in which difficult to obtain because depend of the adjusted the concentration of reacting chemicals and controlled the reaction environment. Thus, the nanoparticles could also be stabilized directly in the process by proteins metabolic pathway [35-37].

To date, several microorganisms from bacteria to fungi have been reported to synthesize inorganic materials either intra- or extracellularly, and thus to be potentially utilized as eco-friendly nano factories [38, 39].

Pseudomonas stutzeri AG259, isolated from silver mines, has been shown to produce silver nanoparticles and the bio reduction of Ag was also reported in Bacillus licheniformis $[40,41]$. In Addition to that, some bacterial genera, like Bacillus, Arthrobacter, Pseudomonas and Escherichia, could induce the synthesis of silver nanoparticles [42].

\subsection{Synthesis of AgNPs using Fungus}

Although several bacteria used in the biological synthesis of AgNPs, the eukaryotic fungal kingdom has been known to secret higher number of bioactive compounds which made fungi more suitable in large scale biomass production in nano factories [43]. And also, the extracellular biosynthesis using fungi could also make down processing much easier than bacterial biosynthesis of nano silver particles. Many fungi have mycelia that provide a much higher surface area than bacteria and this area could be used to support the interaction of metal ions and fungal reducing agent thus enhancing the conversion of ions to metallic nanoparticles sufficiently. Which biosynthesis exceptionally able to easy scale up and economical feasible [44]. Due to this, many researches have in sighted and tend to fungi biosynthesis process. For instance, Fusarium oxysporum and Verticillium species [45, 46], Aspergillus fumigatus [47], Trichoderma reesei [48], Aspergillus niger [49], Aspergillus flavus [50] and Penicillium fellutanum [51]. Fungal spp. has been used commonly in this day for microbial production of silver nanoparticles. However, there is a certain limitation of scientific reports on the finding of novel fungi strains and elucidate mechanism of the biochemical pathway.

\subsection{Synthesis of AgNPs using Plant Extract}

For the last two decades, synthesis of sliver nanoparticles using bacterial and fungus were practiced. Currently, using of plant extract has promised in biological synthesis of metallic nanoparticles [52]. https://doi.org/10.30799/jnst.233.19050211
The plants have produced essential secondary metabolites during their growth like alkaloids, flavonoids, terpenoids and so on. Those pythochemicals are the crucial components and mandate the green synthesis of nanoparticles in reduction and stabilization of metallic ions [53]. As per parashara et al. has proved, small size of silver nanoparticles (10-20 nm) were built by reducing the silver nitrate salt with that of Jatropha curcas extracts in $4 \mathrm{~h}$.

According to this study plant extract has potential to reduce the metallic salts to nano ions in short duration of time along with their desirable size and shape. However, the sample of extract might need heat activation to temperature of $85{ }^{\circ} \mathrm{C}$, which would be fairly costly if high volumes are required in industrial scale production.

\subsection{Key Factors Affecting and Governing Biosynthesis of AgNPs}

It is suggested that different parameters affect the optimum production of silver nanoparticles in biological system. However, the factors which affect the biosynthesis of AgNPs is fluctuate depending upon the kingdom, species and strains that would have been used. In former studies on the biological synthesis of silver and gold nanoparticles using bacteria [54] and fungi [55]. the time required for completion of the reaction ranges from 24 to $120 \mathrm{~h}$, while the $24 \mathrm{~h}$ incubation exhibited maximum synthesis of silver nanoparticles.

Despite the Physio-chemical parameters effect on bacterial different from the fungi, temperature $\left(\mathrm{T}^{0}\right)$, incubation time $(\mathrm{t}), \mathrm{pH}$ and concentration are the predominant factors in the biological synthesis of silver nanoparticles [56-59]

In the existing study, $\mathrm{NADH}$ is the main governing factor is synthesis of AgNPs using Aspergillus terreus. As Guangquan et al., 2012 have been issued that the dialyzed cell filter is induced by NADH and recover the reaction at $440 \mathrm{~nm}$. This result indicated that NADH dependent reductase is might be the key factor in the synthesis of silver nano particles (AgNPs) using Aspergillus terreus.

\section{Biological Application of AgNPs}

Because of their unique molecular arrangement and structural alignment, AgNPs have many applications in biological, agricultural, industrial and biomedical division. Based on the preceding review, silver nanoparticles have been realized on in household utensils, health care industry, and in food storage, environmental, and in biomedical applications, such as a biosensor, anti-microbial, anti-viral, anti-tumor, anti-inflammatory, drug delivery, dental material, textile nano painting [60-65].

\subsection{Nano-Coated Biomedical Tools and Fabrics}

Silver salt was used to as antimicrobial before a century and was very well known effective in treatment of bacterial infection for wound healing. However, its function in the nano size level is not yet commonly understood and the toxic effect of silver nano particles has not been reported in the literatures $[66,67]$.

Antibiotic resistance strains are emerging this year and it is compulsory search out the broad spectrum against pathogens. Updated reports reach out that AgNPs have an inhibitory effect towards many microorganism strains commonly apply in medical and industrial processes. Silver nano particles have high antimicrobial activity against Gram negative and Grampositive bacteria [68]. Therefore, those bio materials coated with AgNPs have a strong bactericidal effect on varieties of application, including wound healing, catheters, dental work, skin ointments, silver-impregnated polymers, silver-embedded fabrics, coatings for medical devices and water treatment filter [69-72].

Nano scale materials fully realized their optical, catalytic and antimicrobial activity as per the size and shape of the particles vary [73]. When the size of the metal nano particles is much diminished, its antimicrobial activity against pathogenic bacterial is strong elicited [74].

Thus, the properties of AgNPs will be effective on the verities of nanomaterials including medical device and industrial tools when it has been well investigated the atomic structure and optical properties of nanoscale particles.

\subsection{Nano-Fertilizer}

The fertility of agriculture soil has depleted against to the potential production of yield as long as the world population growth. Due to starvation of the soil fertility, it is suggested apply soil nutrition to enhance growth germination and yields of different substantial crops. Nano coated nitrogen fertilizer, such as Nano bentonite and Nano active coat does dramatically upturn the absorption and sped up the transportation biochemical pathway of the rice [75]. 
On the hand, silver nanoparticles (SNP) in 25ppm concentration as of fertilizer had studied and found out the result, in which significantly improved above the average of the growth and yield quality of the grain wheat, but not in 75 ppm concentration [76].

\subsection{Nano Oncology (Anti-cancer)}

Induced tumors are proliferated, uncontrolled and leading to morbidity of the cells if could not treat at a target site of a chemical metabolism pathway of cancerous. Today, Nano type medicating is emerging and able to deregulate the expression of the oncogene proteins $[77,78]$. Nanoparticles are applied in target drug discovery and drug delivery of cancer cell since they have very fine particles along their anti-cancer, antibiotic, anti-allergic and anti-inflammatory properties. Based on recent studies, silver nanoparticles (AgNPs) was tested on different cancer cell line like MCF-7 cell, which induce a high cytotoxic effect as the concentration of the particles has increased. Resulting, prodigious morphology and condensed chromatic were recorded. Complete mortality rate on cancer cell line was observed in 50ug.ml of silver nanoparticles [79]. Having that non cytotoxity of normal cell, those biosynthesis of silver nanoparticles is promising in conjugating of drug delivery and gene therapy. In fact, that to date many researches have been conducted and gotten promising insight as descried in Table 1.

Table 1 Silver nanoparticles against cancer cel

\begin{tabular}{|c|c|c|}
\hline AgNPs synthesis rout & Tested cancer cells & Ref. \\
\hline $\begin{array}{l}\text { Leave extract- } \\
\text { S. grandiflora }\end{array}$ & Breast cancer cell line-MCF-7 & {$[80]$} \\
\hline $\begin{array}{l}\text { Plant dandelion- } \\
\text { Taraxacum officinale }\end{array}$ & Human liver cancer cells (HepG2) & [81] \\
\hline $\begin{array}{l}\text { Plant Extract- } \\
\text { Commelina nudiflora L }\end{array}$ & HCT- 116 colon cancer cells & {$[82]$} \\
\hline $\begin{array}{l}\text { plant extracts of guava } \\
\text { and clove }\end{array}$ & $\begin{array}{l}\text { Human colorectal adenocarcinoma, the human } \\
\text { kidney, human chronic myelogenous, leukaemia, } \\
\text { bone marrow, and human cervix }\end{array}$ & [83] \\
\hline $\begin{array}{l}\text { Plant Extract- } \\
\text { Nostoc linckia }\end{array}$ & MCF-7 & {$[84]$} \\
\hline Chemical synthesis & $\begin{array}{l}\text { A549 (Human lung carcinoma), HeLa (Human } \\
\text { cervical adenocarcinoma), MCF7 (Human breast } \\
\text { adenocarcinoma), MDAMB231 (Human breast } \\
\text { adenocarcinoma), and SKBR3 (Human breast } \\
\text { adenocarcinoma) cells }\end{array}$ & {$[85]$} \\
\hline $\begin{array}{l}\text { Plant Extract-ethanolic } \\
\text { extract of rose (Rosa } \\
\text { indica) petals }\end{array}$ & $\begin{array}{l}\text { Human colon adenocarcinoma cancer cell line } \\
\text { HCT } 15\end{array}$ & [86] \\
\hline
\end{tabular}

\subsection{Biosensor}

The price of silver $(\mathrm{Ag})$ is much cheaper than that of gold $(\mathrm{Au})$ for using it as reference and counter electrode accepter in biological catalytically activity or electrochemistry and as silver paint for printed electrical circuit boards [87]. Due to their catalytically properties, silver nanoparticles, is important in molecular diagnosis and biomedical researches. The studies have showed that silver nanoparticles were applied in conjugating of oligonucleotides probe to target DNA hybridization because the DNA duplex will be easily differentiated [88]. However, silver nanoparticles are more sensitive than gold and detected easily due to its greater extinction coefficient [89].

\section{Conclusion}

Production of silver NPs have been increased at industrial level because of their unique properties including catalytic activity, electronic properties, optical properties, magnetic property and anti-microbial activity, and proven applicability in diverse areas such as biomedical material, textile fabrics, nano seed, cosmetic, nano fertilizer or nutrition, electronics, sensor, drug delivery, pesticide and water treatment. Onward that, the size, shape and crystal structure is determined based upon the methods what we used so that unique and the major task in the modern synthesis of nanoparticle is choosing of an advanced and ecofriendly method. Even if we can produce structural nanoparticle in such way, physical and chemical method of synthesis of nanoparticles is too expensive and environmentally unsound.

Currently, the discharge of chemical agents from nano fabrics and impurities of impended product are the main challenge in environmental policy and human health care management. Using of expensive tools, hazard chemicals, heavy ray, sputtering radiation, spray pyrolysis techniques and apply high energy demand is not suggested as good as https://doi.org/10.30799/jnst.233.19050211 green synthesis of silver nanoparticles. However, there is a better possibility of using green synthesis of silver nanoparticles, such as plant, bacterial and fungal production of nanoparticles is emerging as a novel ecofriendly technique. This is why very important methods since remaining impurity of chemical on silver nanoparticles while synthesis or stabilizing might have not cytotoxic effect along cellular machinery. However, among all, they have their own limitation while the mothed will have been applied in industrial high-level production. Though, plant proteins, alkaloids, flavonoids and amino acid are used as reducing agent, vast vegetation and secondary metabolite culture is subjected whereas careful monitoring of culture broth, optimization and voiding of entire contamination is required in the bacterial biosynthesis of silver nanoparticles, but fungal method is fast and cost effective. The reason is the mycelia of the fungus provide a large surface area to diminish silver nitrate solution into silver nanoparticles through extracellular bioactive enzyme activity. Extracellular metabolites have been extracted outside cell membrane and could reduce silver nanoparticles when fungus stressed in silver ion solution. They have surplus biomass production in a short period of time and ease in down streaming processes which is performed without using toxic chemical agent and excessive thermal energy. In addition to that fungus are better tolerance and metallic bio accumulation properties in which fungal is long lasting fermentation till all substrate go down into the desired products. The silver nanoparticles, which has produced through fungal biosynthesis is free from chemical contamination and be considered safe for medical and agricultural use.

\section{Acknowledgement}

I would like to acknowledge all department of biotechnology in Sharda University those gave me unreserved time when I need technical assistance. I also would like to thank to my supervisor Prof. Rita Singh Majumda. I am very grateful for her supervision and guidance during the preparation of my research work. Plus, this is my pleasure to Sharda University which able to organize and kindly invite me to present this paper in 2nd national conference on advance biotechnology: An Interdisciplinary Approach. I was delighted since I have gotten a chance to share my experience.

\section{References}

[1] Z. Shervani, Y. Yamamoto, Carbohydrate-directed synthesis of silver and gold nanoparticles: effect of the structure of carbohydrates and reducing agents on the size and morphology of the composites, Carbohydr. Res. 346 (2011) 651658.

[2] K.B. Narayanan, N. Sakthivel, Biological synthesis of metal nanoparticles by microbes, Adv Colloid Interf. Sci. 156 (2010) 1-13.

[3] P. Dhandapani, A.S. Siddarth, S. Kamalasekaran, S. Maruthamuthu, G. Rajagopal, Bio-approach: ureolytic bacteria mediated synthesis of $\mathrm{ZnO}$ nanocrystals on cotton fabric and evaluation of their antibacterial properties, Carbohydr. Polym. 103 (2014) 448-455.

[4] K. Shameli, M.B. Ahmad, W.M.Z.W. Yunus, N.A. Ibrahim, Y. Gharayebi, S. Sedaghat, Synthesis of silver/montmorillonite nanocomposites using $\gamma$ irradiation, Int. J. Nanomed. 5 (2010) 1067-1077.

[5] R. Chandrasekaran, S. Gnanasekar, P. Seetharaman, R. Keppanan, W.S Arockiaswamy, S. Sivaperumal, Formulation of Carica papaya latexfunctionalized silver nanoparticles for its improved antibacterial and anticancer applications, J. Mol. Liq. 219 (2016) 232-238.

[6] K.B. Narayanan, N. Sakthivel, Green synthesis of biogenic metal nanoparticles by terrestrial and aquatic phototrophic and heterotrophic eukaryotes and biocompatible agents, Adv Colloid Interf. Sci. 169 (2011) 59-79.

[7] M. Gill, Pigments of fungi (Macrocycetes), Nat. Prod. Rep. 16 (1999) 301-17.

[8] L.K. Adams, D.Y. Lyon, P.J.J. Alvarez, Comparative eco-toxicity of nanoscale $\mathrm{TiO}_{2}$ $\mathrm{SiO}_{2}$, and $\mathrm{ZnO}$ water suspensions, Water Res. 40 (2006) 3527-3532.

[9] N. Taniguchi, On the basic concept of 'nano-technology, In Proceedings of the international conference on production engineering Tokyo, Soc. Precis. Eng. 2 (1974) 18-23.

[10] J.H. Fendler, Nanoparticles and nanostructured films: preparation, characterization and applications, John Wiley \& Sons, COUNTRY, 1998.

[11] G. Schmid, Large clusters and colloids, Metals in the embryonic state, Chem Rev. 92 (1992) 1709-1727.

[12] M.C. Daniel, D. Astruc, Gold nanoparticles: assembly, supramolecular chemistry, quantum-size-related properties, and applications toward biology, catalysis, and nanotechnology, Chem. Soc. Rev. 104 (2004) 293-346.

[13] T.S. Wong, U. Schwaneberg, Protein engineering in bio electrocatalysis, Curr Opin. Biotechnol. 14 (2003) 590-596.

[14] A. Ramanaviciusa, Kausaite, A. Ramanaviciene, Enzymatic biofuel cell based on anode and cathode powered by ethanol, Biosens Bioelect. 24 (2008) 761-766.

[15] V. Uskokovic, Challenges for the modern science in it descend towards nano scale, Curr. Nanosci. 5 (2009) 372-389.

[16] K. Deplanche, I. Caldelari, I.P. Mikheenko, F. Sargent, L.E. Macaskie, Involvement of hydrogenases in the formation of highly catalytic Pd (0) nanoparticles by bio reduction of Pd(II) using Escherichia coli mutant strains, Microbiol. 156 (2010) 2630-2640. 
[17] J. Kasthuri, K. Kathiravan, N. Rajendiran, Phyllanthin-assisted biosynthesis of silver and gold nanoparticles: a novel biological approach, J. Nanopart. Res. 11 (2008) 1075-108.

[18] K.C. Bhainsa, S.F. D'Souza, Extracellular biosynthesis of silver nanoparticles using the fungus Aspergillus fumigatus, Colloids Surf. B Biointerf. 47 (2006) 160-164

[19] N. Duran, P.D. Marcarto, G.I.H. De Souza, O.L. Alves, E. Esposito, Antibacterial effect of silver nanoparticles produced by fungal process on textile fabrics and their effluent treatment, J. Biomed. Nanotechnol. 3 (2007) 203-208.

[20] M. Jeyaraj, G. Sathishkumara, Sivanandhana, D. Mubarak Alid, M. Rajesha, et al., Biogenic silver nanoparticles for cancer treatment, Colloids Surf. B: Biointerf. 106 (2013) 86-92.

[21] P. Kumar, M. Govindaraju, S. Senthamilselvi, K. Premkumar, Photocatalytic degradation of methyl orange dye using silver $(\mathrm{Ag})$ nanoparticles synthesized from Ulva lactuca, Colloids Surf. B: Biointerf. 103 (2013) 658-661.

[22] P. Prakash, P. Gnanaprakasam, R. Emmanuel, S. Arokiyaraj, M. Saravanan, Green synthesis of silver nanoparticles from leaf extract of Mimusops elengi, Linn for enhanced antibacterial activity against multi drug resistant clinical isolates, Colloids Surf. B: Biointerf. 108 (2013) 255-259.

[23] J. Tian, K.K.Y. Wong, C.M. Lok, C.N. Ho, W.Y. Yu, et al., Topical delivery of silver nanoparticles promotes wound healing, Chem. Med. Chem. 2 (2007) 129-136

[24] C. Damm, H. Münstedt, A. Rösch, Long-term antimicrobial polyamide 6/silvernanocomposites, J. Mater. Sci. 42 (2007) 6067-6073.

[25] S.L. Percival, P.G. Bowler, D. Russell, Bacterial resistance to silver in wound care, Jour. Hospital Infect. 60 (2005) 1-7.

[26] M. Singh, S. Singh, S. Prasad, I.S. Gambhir, J. Dig, Nanotechnology in medicine and antibacterial effect of silver nanoparticles, Nanomater. Bios. 3 (2008) 115122.

[27] M. Darroudi, M.B. Ahmad, A.K. Zak, R. Zamiri, M. Hakimi, Fabrication and characterization of gelatin stabilized silver nanoparticles under UV-light, Int. J. Mol. Sci. 12 (2011) 6346-6356.

[28] D.S. Kilin, O.V. Prezhdo, Y.N. Xia, Shape-controlled synthesis of silver nanoparticles: Ab initio study of preferential surface coordination with citric acid, Chem. Phys. Lett. 458 (2008) 113-116.

[29] M.S.M. Peterson, J. Bouwman, A. Chen, M. Deutsch, Inorganic metallo dielectric materials fabricated using two single-step methods based on the Tollen's process, J. Colloid Interf. Sci. 306 (2007) 41-49.

[30] S. Iravani, H. Korbekandi, S.V. Mirmohammadi, B. Zolfaghari, Synthesis of silver nanoparticles: chemical, physical and biological methods, Res. Pharm. Sci. 9 (2014) 385-406.

[31] K. Shameli, M.B. Ahmad, W.Z.W. Yunus, N.A. Ibrahim, M. Darroudi, Synthesis and characterization of silver/talc nanocomposites using the wet chemical reduction method, Int. J. Nanomed. 5 (2010) 743-751.

[32] V. Bansal, R. Ramanathan, S.K. Bhargava, Fungus-mediated biological approaches towards "green" synthesis of oxide nanomaterials, Aust. J. Chem. 64 (2011) 279-293.

[33] B.K. Mehta, M. Chhajlani, B.D. Shrivastava, Green synthesis of silver nanoparticles and their characterization by XRD, Jour. Phys. Conf. Series 836 (2017) 012050-1-4.

[34] D. Mandal, M.E. Bolander, D. Mukhopadhyay, G. Sarkar, P. Mukherjee, The use of microorganisms for the formation of metal nanoparticles and their application, Appl. Microbiol. Biotechnol. 69 (2006) 485-492.

[35] M. Kowshik, S. Ashtaputre, S. Kharrazi, W. Vogel, J. Urban, S.K. Kulkarni, K.M Paknikar, Extracellular synthesis of silver nanoparticles by a silver tolerant yeast strain MKY3, Nanotechnol. 14 (2003) 95-100.

[36] M. Sastry, A. Ahmad, N.I. Islam, R. Kumar, Biosynthesis of metal nanoparticles using fungi and actinomycete, Curr. Sci. 85 (2003) 162-170.

[37] N. Durán, P.D. L. Marcato, O. Alves, G.I.H. De Souza, E. Esposito, Mechanistic aspects of biosynthesis of silver nanoparticles by several Fusarium oxysporum strains, J. Nanobiotechnol. 3 (2005) 3-8.

[38] S.S. Shankar, A. Rai, B. Ankamwar, A. Singh, A. Ahmad, M. Sastry, Biological synthesis of triangular gold nanoprisms, Nat. Mater. 3 (2004) 482-488.

[39] P. Mohanpuria, N.K. Rana, S.K. Yadav, Biosynthesis of nanoparticles: Technological concepts and future applications, J. Nanopart. Res. 10 (2008) 507-517.

[40] T. Klaus, R. Joerger, E. Olsson, C.G Granqvist, Silver-based crystalline nanoparticles, microbially fabricated, Proc. Natl. Acad. Sci. USA 96 (1999) 13611-13614.

[41] K. Kalimuthu, R. Suresh Babu, D. Venkataraman, M. Bilal, S. Gurunathan, Biosynthesis of silver nanocrystals by Bacillus licheniformis, Colloids Surf. B Biointerf. 65 (2008) 150-153.

[42] S. Shivaji, S. Madhu, S. Singh, Silver nanoparticles using psychrophilic bacteria, Process Biochem. 46 (2011) 1800-1807.

[43] D. Singh, V. Rathod, S. Ninganagouda, J. Herimath, P. Kulkarni, Biosynthesis of silver nanoparticle by endophytic fungi Penicillium sp. isolated from Curcuma longa (turmeric) and its antibacterial activity against pathogenic gramnegative bacteria, Jour. Pharm. Res. 7 (2013) 448-453.

[44] P. Mukherjee, A. Ahmad, D. Mandal, S. Senapati, S. Sainkar, Fungus mediated syntheses of silver nanoparticles and their immobilizaation in the mycelial matrix- A novel biological apporach to nanoparticle synthesis, Nano Lett. 1 (2001) 515-519.

[45] A. Bharde, D. Rautaray, V. Bansal, A. Ahmad, I. Sarkar, et al., Extracellular biosynthesis of magnetite using fungi, Small 2 (2006) 135-141.

[46] B.D. Sawle, B. Salimath, R. Deshpande, M.D. Bedre, B.K. Prabhakar, A. Venkataraman, Biosynthesis and stabilization of $\mathrm{Au}$ and $\mathrm{Au}-\mathrm{Ag}$ alloy nanoparticles by fungus, Fusarium semitectum, Sci. Technol. Adv. Mater. 9 (2008) 035012-1-6.

[47] P.V. Ratnasri, K.P.J. Hemalatha, Biological synthesis of silver nanoparticles from Aspergillus fumigatus, Am. J. Adv. Drug Deliver. 6 (2014) 741-751.
[48] J.C. Chen, Z.H. Lin, X.X. Ma, Evidence of the Production of silver nanoparticles via pretreatment of phoma sp.3.2883 with silver nitrate, Lett. Appl. Microbiol. 37 (2003) 105-108.

[49] A.K. Gade, P.P. Bonde, A.P. Ingle, P. Marcato, N. Duran, M.K. Rai, Exploitation of Aspergillus niger for synthesis of silver nanoparticles, J. Biobased Mater. Bioenergy. 2 (2008) 1-5.

[50] N. Vigneshwaran, N.M. Ashtaputre, P.V. Varadarajan, R.P. Nachane, K.M. Paralikar, R.H. Balasubramanya, Biological synthesis of silver nanoparticles using the fungus Aspergillus flavus, Mater. Lett. 61 (2007) 1413-1418.

[51] K. Kathiresan, S. Manivannan, M.A. Nabeel, B. Dhivya, Studies on silver nanoparticles synthesized by a marine fungus Penicillium fellutanum isolated from coastal mangrove sediment, Coll. Surf. B Biointerf. 71 (2009) 133-137.

[52] H. Bar, D.K. Bhui, G.P. Sahoo, P. Sarkar, S.P. De, Green synthesis of silver nanoparticles using latex of Jatropha curcas, Colloids Surf. A: Physicochem. Eng. Aspects 339 (2009) 134-139.

[53] U.K. Parashar, V. Kumar, T. Bera, P.S. Saxena, G. Nath, Study of mechanism of enhanced antibacterial activity by green synthesis of silver nanoparticles, Nanotechnol. 22 (2011) 1-13.

[54] K.K.P. Prabhu, Biosynthesis of silver nanoparticles using Lactobacillus acidophilus and white rot fungus - a comparative study, Int. J. Adv. Res. 3 (2017) 299-306.

[55] G. Arun, M. Eyini, P. Gunasekaran, Green synthesis of silver nanoparticles using the mushroom fungus Schizophyllum commune and its biomedical applications, Biotechnol. Bioproc. Eng. 19 (2015) 1083-1090.

[56] H.M.M. Ibrahim, Green synthesis and characterization of silver nanoparticles using banana peel extract and their antimicrobial activity against representative microorganisms, J. Radiat. Res. Appl. Sci. 8 (2015) 265-275.

[57] N. Khatoon, A. Mishra, H. Alam, N. Manzoor, M Sardar, Biosynthesis, characterization, and antifungal activity of the silver nanoparticles against pathogenic candida species, Bio. Nano. Sci. 5 (2015) 65-74.

[58] P.P. Gan, S.F.Y. Li, Potential of plant as a biological factory to synthesize gold and silver nanoparticles and their applications, Rev. Environ. Sci. Biotechnol. 11 (2012) 169-206.

[59] M.A.M. Abo-State, A.M. Partila, Microbial production of silver nanoparticles by P. aeruginosa cell free extract, J. Ecol. Health Environ. 3 (2015) 91-98.

[60] W. Zhou, Y. Ma, H. Yang, Y. Ding, X. Luo, A label-free biosensor based on silver nanoparticles array for clinical detection of serum p53 in head and neck squamous cell carcinoma, Int. J. Nanomed. 6 (2011) 381-386.

[61] P.K. Stoimenov, R.L. Klinger, G.L. Marchin, K.J. Klabunde, Metal oxide nanoparticles as bactericidal agents, Langmuir 18 (2002) 6679-6686.

[62] J.L. Elechiguerra, J.L. Burt, J.R. Morones, A. Camacho-Bragado, X. Gao, Interaction of silver nanoparticles with HIV-1, J. Nanobiotech. 3 (2005) 1-10.

[63] T. Premkumar, Y. Lee, K.E. Geckeler, Macrocycles as a tool: A facile and one pot synthesis of silver nanoparticles using cucurbituril designed for cancer therapeutics. Chem. A Eur. J. 16 (2010) 11563-11566.

[64] S. Silver, Bacterial silver resistance: molecular biology and uses and misuses of silver compounds, FEMS Microbiol. Rev. 27 (2003) 341-353.

[65] M. Walton, Antimicrobial nanosilver coating for commercial ap plications, Adv. Coat Surface Technol. 23 (2010) 5-6.

[66] J.A. Spadaro, T.J. Berger, S.D. Barranco, S.E. Chapin, R.O. Becker, Antibacterial effects of silver electrodes with weak direct current, Microb. Agents Chemother. 6 (1974) 637-642.

[67] R.M. Slawson, J.T Trevors, H. Lee, Silver accumulation and resistance in Pseudomonas stutzeri, Arch. Microbiol. 158 (1992) 398-404.

[68] G. Maribel, D. Jean, G. Stéphane, Synthesis and antibacterial activity of silver nanoparticles against gram-positive and gram-negative bacteria, Nanomed. Nanotechnol. Biol. Med. 8 (2012) 37-45.

[69] J.H. Crabtree, R.J. Burchette, R.A. Siddiqi, I.T. Huen, L.L. Handott, A. Fishman, The efficacy of silver-ion implanted catheters in reducing peritoneal dialysisrelated infections, Perit Dial Int. 23 (2003) 368-74.

[70] J.S. Kim, Antimicrobial effects of silver nanoparticles, Nanomed. 3 (2007) 95101.

[71] M. Bosetti, A. Masse, E. Tobin, M. Cannas, Silver coated materials for external fixation devices: in vitro biocompatibility and genotoxicity, Biomater. 23 (2002)) 887-892

[72] M.L. Morrison, R.A. Buchanan, P.K. Liaw, C.J. Berry, R.L. Brigmon, L. Riester, Electrochemical and antimicrobial properties of diamondlike carbon-metal composite films, Diam. Relat. Mater. 15 (2006) 138-146.

[73] C. Burda, X. Chen, R. Narayanan, M.A. El-Sayed, Chemistry and properties of nanocrystals of different shapes, Chem. Rev. 105 (2005) 1025-1102.

[74] L.Z. Zhang, J.C. Yu, H.Y. Yip, Q. Li, K.W. Kwong, A.W. Xu, Ambient light reduction strategy to synthesize silver nanoparticles and silvercoated $\mathrm{TiO}_{2}$ with enhanced photocatalytic and bactericidal activities, Langmuir 19 (2003) 10372-10380.

[75] X. Wang, S. Hai-Xing, L. Qiang, R. Xiang-Min, P. Jian-Wei, et al., Effects of nanopreparation coated nitrogen fertilizer on nutrient absorption and yield of earlyrice, Hunan Agri. Sci. 11 (2011) 1-4.

[76] H. Muhammad, Silver nano-particles enhance the growth, yield and nutrient use efficiency of wheat, Int. J. Agronom. Agri. Res. 7 (2015) 15-22.

[77] M.V. Yezhelyev, X. Gao, Y. Xing, A. Al-Hajj, S. Nie, R.M. O’Regan, Emerging use of nanoparticles in diagnosis and treatment of breast cancer, Lancet Oncol. 7 (2006) 657-667.

[78] R. Jason, Mann, N. Raymond, DuBois, Cancer chemoprevention: myth or reality? Drug Discovery Today: Therapeutic Strategies 1 (2004) 403-410.

[79] M.A. Franco-Molina, E. Mendoza-Gamboa, C.A. Sierra-Rivera, Antitumor activity of colloidal silver on MCF-7 human breast cancer cells, J. Exp. Clin. Cancer Res. 29 (2010) 148-154.

[80] M. Alaa, Shawkey, A. Mohamed, Rabeh, K. Abeer, Abdulall O. Ashraf, Abdellatif, Anticancer activity of silver nanoparticles using Citrullus colocynthis aqueous extracts, Green Nanotech. Adv. Life Sci. Tech. 13 (2013) 2224-7181. 
[81] R.G. Saratale, G. Benelli, G. Kumar, D.S. Kim, G.D. Saratale, Bio fabrication of silver nanoparticles using the leaf extract of an ancient herbal medicine, dandelion (Taraxacum officinale), evaluation of their antioxidant, anticancer potential, and antimicrobial activity against phytopathogens, Environ. Sci. Pollut. Res. Int. 11 (2017) 10392-10406.

[82] P. Kuppusamy, S.J. Ichwan, P.N. Al-Zikri, W.H. Suriyah, I. Soundharrajan, In vitro anticancer activity of $\mathrm{Au}, \mathrm{Ag}$ nanoparticles synthesized using Commelina nudiflora L. aqueous extract against HCT-116 Colon Cancer Cells, Biol. Trace Elem. Res. 173(2) (2016) 305-343.

[83] D. Raghunandan, B. Ravishankar, G. Sharanbasava, D.B. Mahesh, V. Harsoor, Anti-cancer studies of noble metal nanoparticles synthesized using different plant extracts, Cancer Nanotechnol. 2 (2011) 57-65.

[84] S. Rajeshkumar, Green synthesis of different sized antimicrobial silver nanoparticles using different parts of plants- A Review, Int. J. ChemTech Res. 9 (2016) 197-208.
[85] N.E. El-Naggar, M.H. Hussein, A.A. El-Sawah, Bio-fabrication of silver nanoparticles by phycocyanin, characterization, in vitro anticancer activity against breast cancer cell line and in vivo cytotoxicity, Sci Rep. 7 (2017) 1084410845.

[86] S.P. Dubey, M. Lahtinen, M. Sillanp, Green synthesis and characterizations of silver and gold nanoparticles using leaf extract of Rosa rugose, Colloid. Surf. A: Physicochem. Eng. Aspects. 364 (2010) 34-41.

[87] W.B. Wang, D.C. Ni, N.H. Lu, Q.Y. Pang, Z.J. Huang, J.W. Zhao, Preparation of mesoporous $\mathrm{NiO}$ with a bimodal pore size distribution and application in electrochemical capacitors, Electrochim. Acta 55 (2010) 6830-6835.

[88] Y.C. Cao, R. Jin, C.S. Thaxtonm, C.A. Mirkin, A two-color-change, nanoparticlebased method for DNA detection, Talanta 67 (2005) 449-455.

[89] D.G. Thompson, A. Enright, K. Faulds, W.E. Smith, D. Graham, Ultrasensitive DNA detection using oligonucleotide-silver nanoparticle conjugates, Anal. Chem. 80(8) (2008) 2805-2810. 